\title{
A Novel T-C-T Solar Photovoltaic Array Configurations using Rearrangement of PV Modules with Shade Dispersion Technique for Enhancing the Array Power
}

\author{
V. Bala Raju, Ch. Chengaiah
}

\begin{abstract}
Total-Cross-Tied (TCT) solar array configuration has more output power under uniform irradiance condition (un-shade case) among all conventional solar photovoltaic (SPV) array configurations but reduced array power under non-uniform irradiance cases (shading cases). To improve the performance of TCT array configuration under shading cases by using rearrangement or repositioning of existing photovoltaic (PV) modules in TCT configuration to new optimal locations within a TCT array configuration with shade dispersion technique. In this rearranged method, repositioning the modules based on puzzle pattern without altering the electrical connections among modules in an SPV array. The shading on $P V$ modules are dispersed by changing the position of $P V$ modules to optimal locations within SPV array so the performance of conventional TCT configuration will be improved. In this paper proposed an optimal TCT configurations, it requires a minimum number of electrical connections or ties between array modules and it depends on the shaded modules location in SPV array and also the proposed method reduces the wiring losses, mismatch losses. For this analysis, MATLAB/Simulink software is used for modeling and simulation of $6 x 6$ size different rearrangement based TCT and proposed optimal SPV array configurations under one un-shaded case and fourteen different shading cases.
\end{abstract}

Keywords- PV modules, array power, optimal interconnections, wiring losses, Partial shading cases, shaded modules.

\section{INTRODUCTION}

The Sun light consists of photons falls on a solar photovoltaic cells converts into electricity by photovoltaic effect. The number of series connected PV cells are formed to a single PV module and it produces a small amount of energy. The modules are connected in series and/ or parallel connection has produces higher amounts of energy as a solar array. The direct current (DC) generated from solar modules are converted to alternating current $(\mathrm{AC})$ by using inverters and these converted $\mathrm{AC}$ electricity from the inverter is used for our applications and or sent to the electrical grid for use elsewhere[1-2].
The performance of Solar PV system mainly depends on shading, soiling, faulty strings, bypassed modules, degradation of modules, operating temperature [3-4]. The efficiency of PV modules is less than $21 \%$ under un-shaded case with full irradiance of $1000 \mathrm{~W} / \mathrm{m}^{2}$. The SPV array power is reduced due to partial shading effect. To improve the array power under partial shading (non-uniform irradiances), new TCT configurations or topology are proposed in this paper. The proposed configurations are developed by changing the location of SPV modules without altering the electrical interconnections among modules in array configurations. The proposed new TCT array topologies are mainly Optimal TCT, Modified TCT, new re-arranged TCT, Zig-Zag TCT, Modified Magic Square(MS) TCT, Half reconfigure TCT, Full reconfigure TCT, Tom-Tom puzzle based TCT, New cross- diagonal TCT and Ken-Do-Ku puzzle based TCT array configurations [5-10] are developed in this paper. The proposed new TCT configurations are developed based on puzzle number arrangement by shaded dispersion technique without altering the module to module connections in SPV array. The every PV module in array are re-positioning to optimal location and this optimal location is determined based on shadow pattern within the array.

As compared to other configurations the TCT has minimum mismatch losses under various shading scenarios as presented in different literature research work [10-15]. This paper proposes an optimal interconnections (or ties) for a $6 \times 6$ size TCT array configurations and analyze the performance under 14 different possible partial shading conditions. The proposed optimal connection method improves the performance of different configurations as compared to series-parallel configuration and new puzzle number arrangement based TCT configurations. The proposed optimal method creates an alternative path for current distribution between modules under un-shaded and partial shaded conditions with minimum number of interconnections or ties in the 6x6 size solar photovoltaic array system. The proposed method minimizes the wiring time during installation, installation cost of PV system and complexity of interconnections among modules as compared to TCT configuration.
Revised Manuscript Received on February 5, 2020.

* Correspondence Author

V. Bala Raju, Research Scholar, Dept. of EEE, SVU College of Engg., SV University, Tirupati. Email: vbrajuu@gmail.com

Dr. Ch. Chengaiah, Professor, Dept. of EEE, SVU College of Engg., SV University, Tirupati

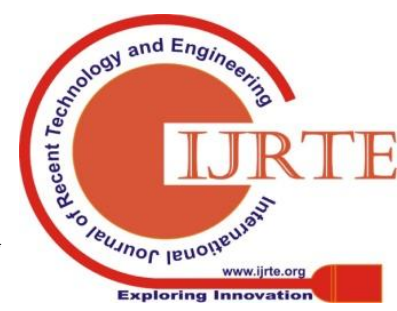


A Novel T-C-T Solar Photovoltaic Array Configurations using Rearrangement of PV Modules with Shade Dispersion Technique for Enhancing the Array Power

\section{MATHEMATICAL MODELING}

\subsection{Formation of Solar photovoltaic arrays:}

Solar PV cells directly converts sun light into electricity by photovoltaic effect [1]. The number of Photoivoltaic cells connected in series to form single PV module and number of PV modules connected in series and or parallel to form solar PV array as shown in fig-1.

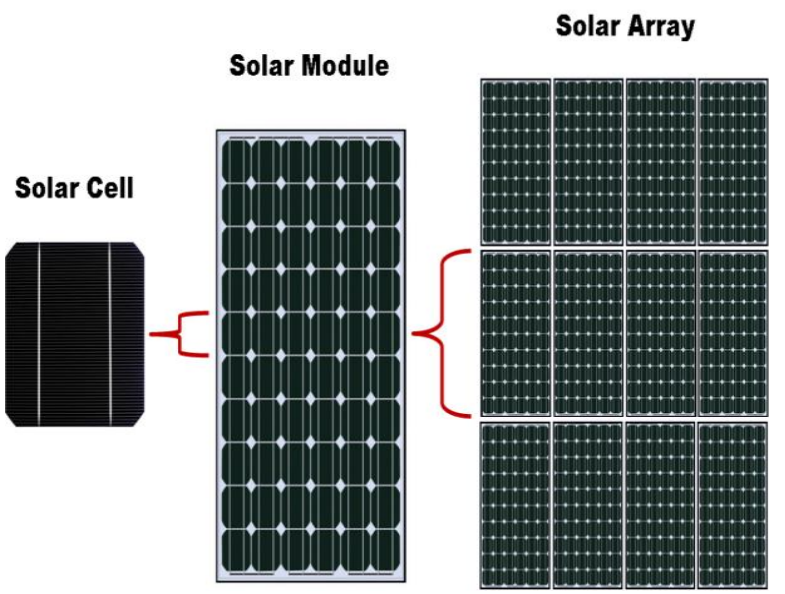

Figure-1: Solar PV Cell to Array formation

\subsection{Mathematical modeling of PV cell and Array}

The single diode equivalent circuit and symbol of a PV cell as shown in figure-2(a) and 2(b).

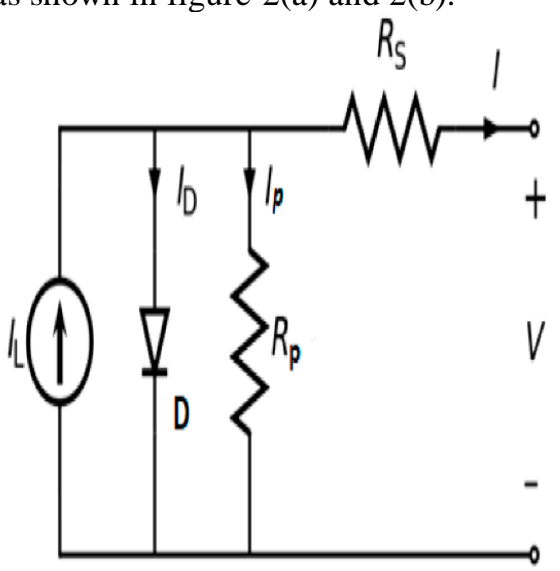

(a)

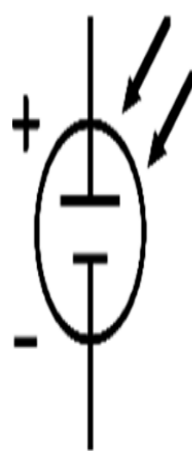

(b)
Figure-2 (a) Solar PV cell (b) Symbol

The mathematical representation of solar photovoltaic cell (PV cell) is given by in equation-a [11].

$I=I_{L}-I_{0}\left[\exp \left\{\frac{q\left(V+I_{s}\right)}{K_{a} T_{c}}-1\right\}\right]-\frac{\left(V+I_{s}\right)}{R_{F}}$

$\mathrm{I}_{\mathrm{L}}$ is module light generated current, represented as

$I_{L}=\frac{G}{G_{0}}\left[I_{L S T C}+K_{i s c}\left(T_{c}-T_{S T C}\right)\right]$

\subsection{Photovoltaic Array modeling:}

The solar PV array with number of series connected modules $\left(\mathrm{N}_{\mathrm{S}}\right)$ and number of parallel connected modules $\left(\mathrm{N}_{\mathrm{P}}\right)$ are represent in figure- 3 .

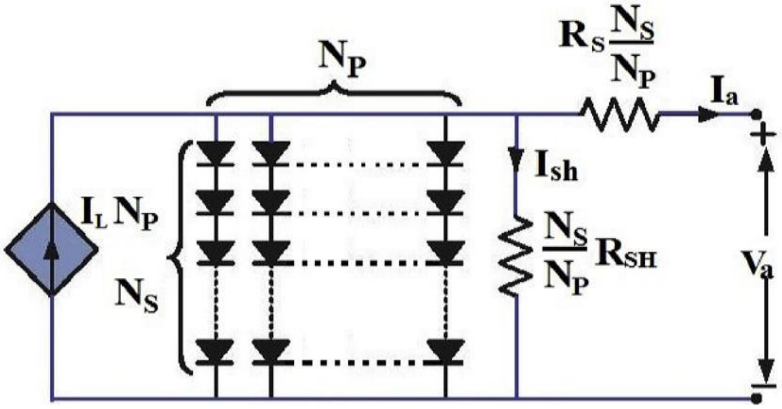

Figure-3: Solar PV Array with number of modules The SPV array represented in mathematically as given in equation-1.

$I_{a}=N_{P} \cdot I_{L}-N_{P} \cdot I_{0} \exp \left\{\frac{q\left(V_{a}+\frac{N_{S}}{N_{P}} I_{a} R_{S}\right)}{N_{S} k a T_{C}}-1\right\}-\frac{\left(V_{a}+\frac{N_{S}}{N_{P}} I_{a} R_{S}\right)}{\frac{N_{S}}{N_{P}} R_{S H}}$

Where $\mathrm{I}_{\mathrm{a}}$ : array output current[A], $\mathrm{V}_{\mathrm{b}}$ : array voltage[V], $\mathrm{I}_{\mathrm{L}}$ : module light generated current $[\mathrm{A}], \mathrm{I}_{0}$ : reverse saturation current of diode $[\mathrm{A}], \mathrm{R}_{\mathrm{S}}$ : series resistance,[$[\Omega], \mathrm{R}_{\mathrm{SH}}$ : Shunt resistance $[\Omega]$, A: Ideality factor of $\mathrm{P}-\mathrm{N}$ junction solar cell diode (value 1-5), $\mathrm{V}_{\mathrm{Th}}$ : Cell thermal voltage[V] as $\mathrm{V}_{\mathrm{Th}}=\mathrm{k}_{\mathrm{a}}$ $\mathrm{T}_{\mathrm{C}} / \mathrm{q}$, where $\mathrm{k}_{\mathrm{a}}$ : Boltzmann's constant [ 1.380658e-23 J/K][4], $\mathrm{T}_{\mathrm{C}}$ : operating temperature $[\mathrm{K}], \quad \mathrm{q}$ :Electron charge [1.60217733e-19 Cb],

\section{SYSTEM DESIGN}

\subsection{Simple 6x6 size photovoltaic system}

The figure- 4 shows the $\mathrm{M} \times \mathrm{N}$ size $(\mathrm{M}=6$ number of modules connected in one string and $\mathrm{N}=6$ number of parallel connected strings) PV system with series-parallel(S-P) configuration with grid integration through power electronics interface devices. In this paper, only different types of SPV array configurations are considered for analyzing optimal connections in different configurations.

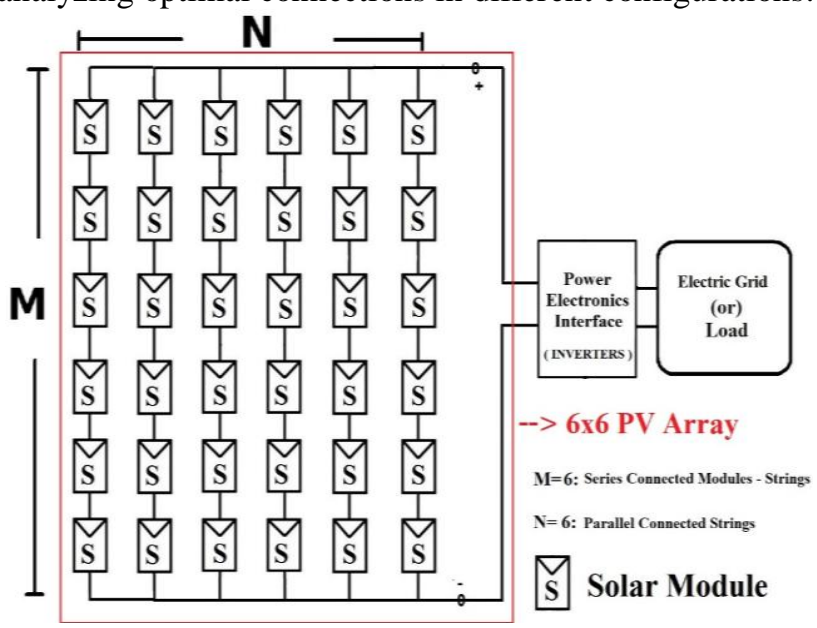

Figure-4. 6x6 size Series-Parallel PV Plant

\subsection{Specifications of PV model:}

For modeling of 6x6 size SPV array system in MATLAB/ Simulink environment, Vikram Solar ELDORA $270 \mathrm{PV}$ module under STC $\left(1000 \mathrm{~W} / \mathrm{m}^{2}\right.$ and $\left.25^{\circ} \mathrm{C}\right)$ parameters are used for the designing of different proposed new TCT array topologies are tabulated in table1.

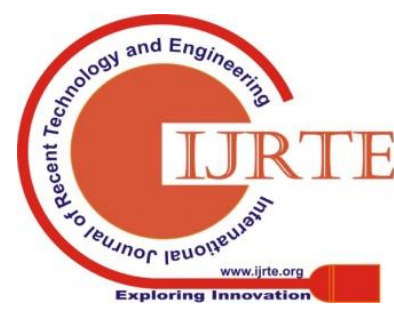


Table 1: Specifications of Vikram Solar ELDORA 270 PV module

\begin{tabular}{llll}
\hline Parameters & & Values \\
\hline Maximum Power & & $270 \mathrm{~W}$ \\
Cells per module & $\mathrm{N}_{\text {cell }}$ & 72 \\
Open circuit voltage & $\mathrm{V}_{\mathrm{OC}}$ & $44 \mathrm{~V}$ \\
Short-circuit current & $\mathrm{I}_{\mathrm{SC}}$ & $8.1 \mathrm{~A}$ \\
Voltage at maximum power point & $\mathrm{V}_{\mathrm{MP}}$ & $34.7 \mathrm{~V}$ \\
Current at maximum power point & $\mathrm{I}_{\mathrm{MP}}$ & $7.8 \mathrm{~A}$ \\
Temperature coefficient of & $\mathrm{V}_{\mathrm{oc}}$ & $-0.3583 \% /{ }^{\circ} \mathrm{C}$ \\
Temperature coefficient of & $\mathrm{I}_{\mathrm{sc}}$ & $0.024975 \% /{ }^{\circ} \mathrm{C}$ \\
Light generated current & $\mathrm{I}_{\mathrm{L}}$ & $8.1924 \mathrm{~A}$ \\
Diode saturation current & $\mathrm{I}_{\mathrm{o}}$ & $2.4871 \mathrm{e}-10$ \\
Diode ideality factor & & 0.98223 \\
Shunt resistance & $\mathrm{R}_{\mathrm{sh}}$ & $3126.5623 \Omega$ \\
Series resistance & $\mathrm{R}_{\mathrm{s}}$ & $0.52303 \Omega$ \\
Module Area (LxWxH) mm & & $1955 \times 982 \times 36$ \\
\hline
\end{tabular}

\subsection{Solar PV Array configurations or topologies}

The main conventional configurations are,
a. Parallel $(\mathrm{P})$ connection
b. Series(S) connection
c. Series-Parallel (S-P) connection
d. Honey-Comb (H-C) connection
e. Bridge-Linked (B-L) connection and
f. Total-Cross-Tied (T-C-T) connection.

Modules are connected in series named as series connection and modules are connected in parallel named as parallel connection topology. In SP connection, first modules are connected in series and then connected to parallel [5-6]. In TCT type of connection, ties are connected among modules to get more power. The BL type is formed by bridge shape of connection and $\mathrm{HC}$ is the hexagon shape of architecture. Different types of SPV topologies are presented in figure-5.

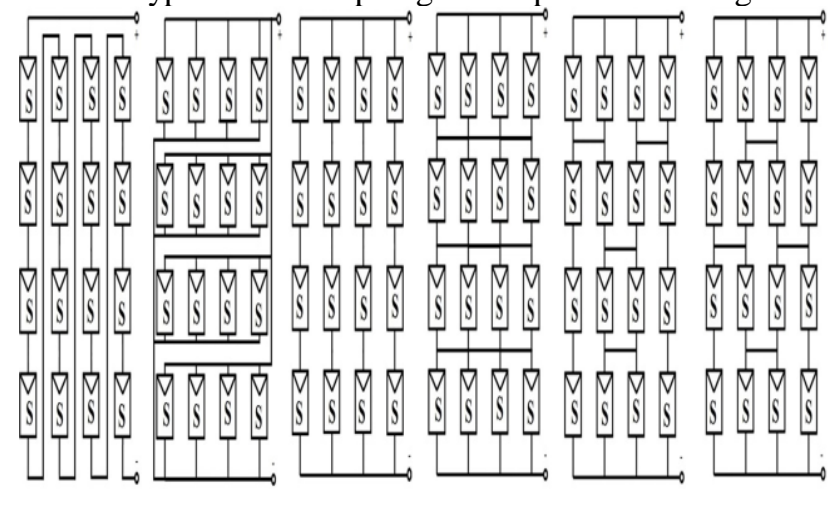

(a) Series array (b) Parallel array (c)S.P array (d) TCT Array (e) HC array (f) BL array

Figure-5: Connection diagram of SPV Array Topologies

3.4: The Proposed new TCT topologies are mainly:
i. Optimal TCT
ii. Modified TCT
iii. New re-arranged TCT
iv. Zig-Zag TCT
v. Modified magic square (MS) TCT
vi. Half Reconfigure TCT
vii. Full Reconfigure TCT
viii. Tom-tom puzzle based TCT
ix. New diagonal based TCT
x. Ken Do Ku puzzle TCT

The above proposed new configurations are based on puzzle pattern arrangement. In each type of arrangement, the modules present in each row and columns are re positioning to new row or column in an array based on puzzle number method. In this method, the electrical connections between module to module in SPV array configuration are un-changed and repositioning the existing modules to new optimal location according to puzzle numbers [5-7]. In the proposed configurations, the performance of conventional TCT configuration under partial shading conditions are improved.

\section{6: Proposed Optimal Configuration}

The proposed optimal configuration is formed by development of optimal number of interconnections in TCT connection with connection switch (CS) technique as discussed in section 4.1 and tabulated the results in Table- 2 .

\section{PROPOSED OPTIMAL TCT CONFIGURATION}

\subsection{Methodology}

In the proposed optimal interconnections among modules, the entire PV array (any PV plant from few KW to MW) is sub divided into a small $2 \times 2$ size sub arrays. The simulation results of a $2 \times 2$ sub array with connection switch $(\mathrm{CS}=0 / 1)$ analysis [10] i.e., if tie/connection is present $(\mathrm{CS}=1)$, absent $(\mathrm{CS}=0)$ among the modules under seven possible shading cases for irradiances $500 \mathrm{~W} / \mathrm{m}^{2}$ and $700 \mathrm{~W} / \mathrm{m}^{2}$ are tabulated in Table-2. The possible seven cases of a $2 \times 2$ sub array with PV modules S1, S2, S3 and S4 are shown in figure-6[10]. In Case-I, all modules in the array receives uniform irradiance of $1000 \mathrm{~W} / \mathrm{m}^{2}$. The maximum power obtained under uniform case with and without tie/connection is equal to $6676 \mathrm{~W}$, in this case a tie or interconnection not required in between modules. In Case II, shaded module S1 receives irradiance of $500 \mathrm{~W} / \mathrm{m}^{2}$ and remaining three modules receives full irradiance of $1000 \mathrm{~W} / \mathrm{m}^{2}$. The power obtained without tie is less than with tie, so in this case a tie is required among the modules.

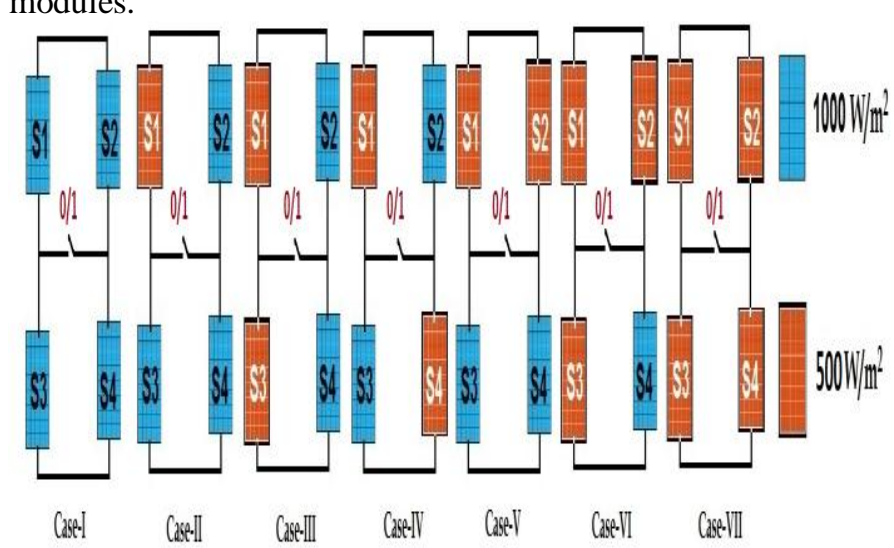

Figure-6. 2x2 PV Array with possible shading cases

In Case-III, IV and V: two modules are shaded in vertical position (S1, S3), diagonally (S1, S4) and horizontal position $(\mathrm{S} 1, \mathrm{~S} 2)$ as shown in figure-4. If two modules are shaded horizontal or vertical position out of four, in this case the output power is same, so a tie may be omitted. 
If the diagonally opposite connected shaded modules are present, a tie among the modules is required to get more maximum power.

In Case VI: modules S1, S2 and S3are shaded and module S4 is un-shaded. The obtained output power of array is more with tie, so that a tie is required in between the modules. In Case-VII: all four modules are shaded. The obtained maximum power of array with and without tie are same, so a tie is not required among the modules in an array.

Out of seven possible shading cases: in cases I, III, V and VII only tie is not required due to the maximum power obtained is equal with and without tie and in cases-II, IV, VI, the maximum power output is less without tie so that a tie required in between modules. It is observed that the obtained maximum power from array is depends on position of number of shaded modules. In proposed method, most of the cases a tie is not required and number of interconnections among the modules are reduced in the PV Array. From the Table-2, it is concluded that if one module shaded or two diagonally shaded modules or three module shaded case the tie is required and for other cases interconnections or ties is not necessary in between modules in an array.

Table-2. Maximum power of different irradiance level cases

\begin{tabular}{|c|c|c|c|c|c|c|}
\hline \multirow[t]{2}{*}{ Case } & \multirow[t]{2}{*}{ Shadowtype } & \multicolumn{2}{|c|}{$\begin{array}{l}\text { Marimum Porter } \mathrm{P}_{\mathrm{w}}(\mathrm{W}) \text { of } \\
\text { shaded modules of irryadiance } \\
500 \mathrm{~W} / \mathrm{m}^{4}\end{array}$} & \multicolumn{2}{|c|}{$\begin{array}{l}\text { Maximum Power } \mathrm{P}_{\mathrm{m}}(\mathrm{W}) \text { of } \\
\text { shaded moduldes of irrradiance } \\
7000 \mathrm{~W} / \mathrm{m}^{2}\end{array}$} & \multirow[t]{2}{*}{$\begin{array}{c}\text { Tie } \\
\text { Required } \\
\text { (Yes:No) }\end{array}$} \\
\hline & & $Q=0$ & $C S=1$ & $C S=0$ & $C S=1$ & \\
\hline I & No Shade & 1062 & 1062 & 1062 & 1062 & No \\
\hline II & One shaded module & 815 & 851.5 & 930.2 & 948.4 & Yes \\
\hline III & Two shaded modules in Serties & 801.6 & 801.6 & 908.1 & 908.1 & No \\
\hline IV & Two diagonally shaded modules & 589.8 & 801.6 & 804.3 & 908.1 & Yes \\
\hline V & Two shaded modulues in Parallel & 589.8 & 589.8 & 804.3 & 804.3 & No \\
\hline VI & There Shaded module & 560.6 & 579.2 & 776.9 & 790.9 & Yes \\
\hline VII & All modules are shaded & 542.7 & 542.7 & 755.3 & 755.3 & No \\
\hline
\end{tabular}

\subsection{Modeling of optimal interconnection TCT array} configuration for shading cases 4 and 6:

The modeling of $6 \times 6$ size proposed optimal TCT configuration for cases 4 and 6 are presented in this section. The required number of ties or interconnections between array modules for SP, TCT and optimal TCT configurations for cases 4 and 6 are tabulated in Table- 3 and for all cases 1 to 14 are tabulated in Table- 4 .

In this proposed method, the entire $6 \times 6$ array is separated into $2 \times 2$ size PV arrays and optimize the required number of interconnections or ties with proposed connection switch (CS) method as discussed in section 4.1. $\mathrm{CS}=1$ means tie present and $\mathrm{CS}=0$ means tie absent between modules. Where a, b, c, d, e, f, g, h, i, j, k, l, m, n, o, p, q, r, s, t, u, v, w, x and $\mathrm{y}$ are the proposed interconnections or ties among the modules in 6x6 size PV system as shown in figure-7. The number of ties required in SP configuration is 0 and in TCT configurations is 25 . In the proposed optimal array configuration, the number of ties required depends upon the shaded modules. If the shaded modules in $2 \times 2$ SPV array are one or diagonal shaded two modules or three modules shaded then tie or interconnection required and in other cases i.e., two shaded modules either horizontal shaded or vertical shaded, all four modules shaded or un-shaded conditions in this case the ties are not required in an array and reduces the wiring losses, wiring cost at the time of installation [12].

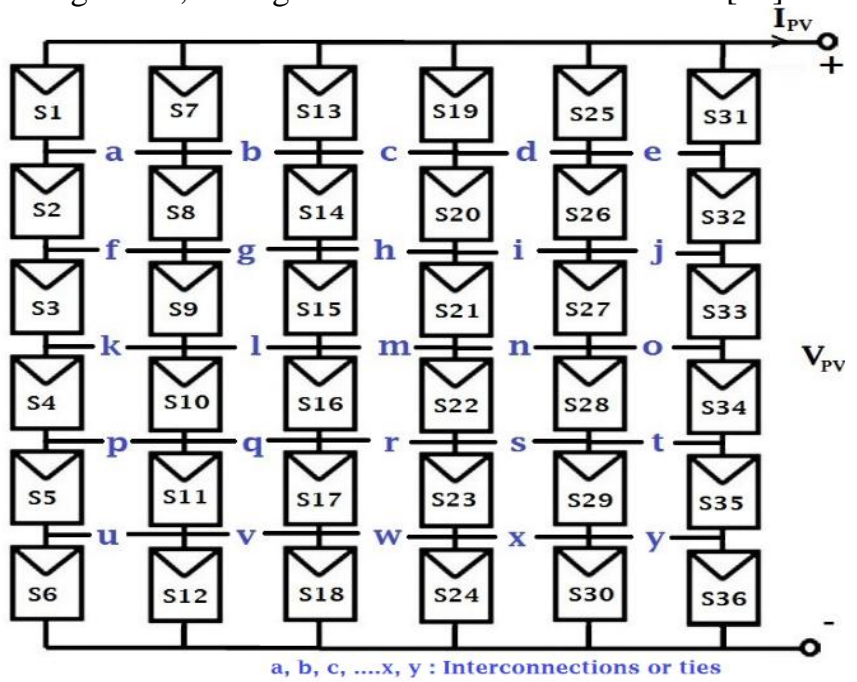

Figure-7: 6x6 size PV Array interconnections among modules

Table-3. Optimal interconnection results for case-2

\begin{tabular}{|c|c|c|}
\hline \multirow[b]{2}{*}{ Configurations } & \multicolumn{2}{|l|}{ 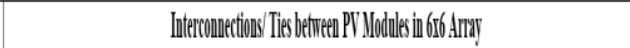 } \\
\hline & 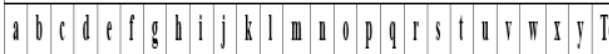 & Total \\
\hline SP & 0000000000000000000000000 & 1 \\
\hline 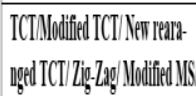 & & \\
\hline 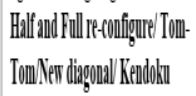 & 1111111111111111111111111 & 15 \\
\hline Optimal TCT & & \\
\hline Forcaset & 1100011100011100011100011 & 13 \\
\hline Forcase-6 & 0000001100000000000001000 & $\mathbb{B}$ \\
\hline
\end{tabular}

The power output of proposed optimal SPV array topology is more than SP configuration and less than TCT topology. By considering wiring losses of rearranged based TCT configurations, the power output of proposed optimal method of configuration is almost equal to that of TCT configuration. The proposed partial shading cases (1 to 14) of different topologies are shown in figure-8.

Table-4. Optimal interconnection results for different cases

\begin{tabular}{|c|c|c|c|c|c|c|c|c|c|c|c|c|c|c|c|c|c|c|c|c|c|c|c|c|c|}
\hline \multirow[b]{2}{*}{ Cases } & \multicolumn{25}{|c|}{ Interconnections/ Ties between PV Modules in 6×6 Array } \\
\hline & a & b & c & d & e & $\mathrm{f}$ & g & h & $\mathrm{i}$ & $\mathrm{j}$ & $\mathrm{k}$ & 1 & m & n & \begin{tabular}{l|l}
0 & 1 \\
\end{tabular} & \begin{tabular}{l|l}
$p$ & $q$ \\
\end{tabular} & $r$ & 5 & $t$ & u & $\mathrm{V}$ & W & $\mathbf{x}$ & $y$ & Total \\
\hline $\mathrm{U}$ & 0 & 0 & 0 & 0 & 0 & 0 & 0 & 0 & 0 & 0 & 0 & 0 & 0 & 0 & 0 & 00 & 0 & 0 & 0 & 0 & 0 & 0 & 0 & 0 & 0 \\
\hline 1 & 0 & 0 & 0 & 0 & 0 & 0 & 0 & 0 & 0 & 0 & 0 & 0 & 0 & 0 & 0 & $\begin{array}{lll}0 & 0\end{array}$ & 0 & 0 & 0 & 0 & 0 & 0 & 0 & 0 & 0 \\
\hline 2 & 0 & 0 & 0 & 0 & 0 & 0 & 0 & 0 & 0 & 0 & 0 & 0 & 0 & 0 & 0 & $\begin{array}{lll}0 & 0\end{array}$ & 0 & 0 & 0 & 0 & 0 & 0 & 0 & 0 & 0 \\
\hline 3 & 0 & 1 & 1 & 1 & 0 & 1 & 0 & 1 & 1 & 1 & 1 & 1 & 0 & 0 & 0 & $\begin{array}{ll}0 & 1\end{array}$ & 1 & 11 & 1 & 1 & 1 & 1 & 1 & 0 & 17 \\
\hline 4 & 1 & 1 & 0 & 0 & 0 & 1 & 1 & 1 & 0 & 0 & 0 & 1 & 1 & 1 & 0 & $\begin{array}{lll}0 & 0\end{array}$ & 1 & 1 & 1 & 0 & 0 & 0 & 1 & 1 & 13 \\
\hline 5 & 0 & 0 & 0 & 0 & 0 & 1 & 1 & 0 & 0 & 0 & 1 & 0 & 0 & 0 & 0 & $\begin{array}{lll}0 & 0\end{array}$ & 0 & 0 & 0 & 0 & 0 & 0 & 0 & 0 & 03 \\
\hline 6 & 0 & 0 & 0 & 0 & 0 & 0 & 1 & 1 & 0 & 0 & 0 & 0 & 0 & 0 & 0 & $\begin{array}{lll}0 & 0\end{array}$ & 0 & 0 & 0 & 0 & 1 & 0 & 0 & 0 & 03 \\
\hline 7 & 0 & 0 & 0 & 0 & 0 & 0 & 0 & 0 & 0 & 0 & 0 & 1 & 0 & 0 & 0 & $\begin{array}{ll}0 & 1\end{array}$ & 10 & 0 & 0 & 0 & 0 & 0 & 0 & 0 & 02 \\
\hline 8 & 0 & 0 & 0 & 0 & 0 & 0 & 0 & 0 & 0 & 0 & 0 & 1 & 0 & 0 & 0 & $\begin{array}{lll}0 & 0\end{array}$ & 0 & 0 & 0 & 0 & 0 & 0 & 0 & 0 & 01 \\
\hline 9 & 1 & 0 & 0 & 0 & 1 & 0 & 0 & 0 & 0 & 0 & 0 & 0 & 0 & 0 & 0 & $\begin{array}{lll}0 & 0\end{array}$ & 0 & 0 & 00 & 1 & 0 & 0 & 0 & 1 & 04 \\
\hline 10 & 1 & 0 & 0 & 0 & 1 & 0 & 0 & 0 & 0 & 0 & 0 & 0 & 0 & 0 & 0 & $\begin{array}{lll}0 & 0\end{array}$ & 0 & 0 & 0 & 1 & 0 & 0 & 0 & 1 & 04 \\
\hline 11 & 0 & 0 & 0 & 0 & 0 & 0 & 0 & 0 & 0 & 0 & 0 & 0 & 0 & 0 & 0 & $\begin{array}{lll}0 & 0\end{array}$ & 0 & 0 & 00 & 0 & 0 & 0 & 0 & 0 & 0 \\
\hline 12 & 1 & 1 & 0 & 1 & 1 & 1 & 1 & 0 & 1 & 1 & 0 & 0 & 0 & 0 & 0 & 11 & 10 & 1 & 1 & 1 & 1 & 0 & 1 & 1 & 16 \\
\hline 13 & 1 & 0 & 0 & 0 & 0 & 0 & 0 & 0 & 0 & 0 & 0 & 0 & 0 & 0 & 0 & $\begin{array}{lll}0 & 0\end{array}$ & 0 & 0 & $\begin{array}{lll}0 & 0\end{array}$ & 0 & 0 & 0 & 0 & 0 & 01 \\
\hline 14 & 1 & 1 & 0 & 0 & 0 & 0 & 1 & 1 & 0 & 0 & 0 & 0 & 1 & 1 & 0 & $\begin{array}{lll}0 & 0 \\
\end{array}$ & 0 & $\begin{array}{ll}0 & 1 \\
0\end{array}$ & 11 & 10 & 0 & 0 & 0 & 1 & 09 \\
\hline
\end{tabular}




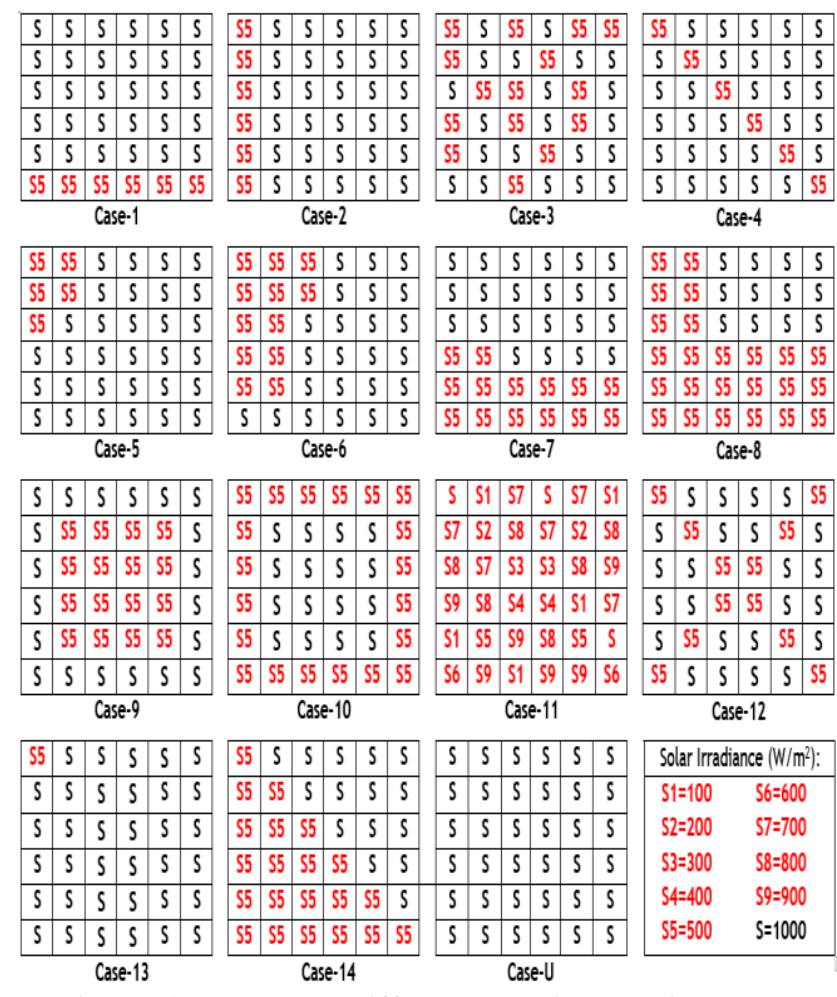

Figure-8. Proposed different partial shading cases

The irradiance received by an array is less than $1000 \mathrm{~W} / \mathrm{m}^{2}$ due to the shading of modules. The main reason for shading is due to changes in tilt angles of modules, shading nearby buildings, clouds, bird litters, falling tree leaves on modules, dust formed on modules because of pollution [5-7]. In this work, for performance analysis of 6x6 size re-arrangement based TCT array configurations and proposed optimal TCT configurations, total fourteen number of proposed shading cases and one un-shaded case (case- $\mathrm{U}$ ) are considered and the results i.e., global maximum peak array power, shading losses, Fill-Factor, efficiency and number of ties among modules are tabulated in Table-5. In un-shaded case-U, all array modules received full irradiance $(S)$ of $1000 \mathrm{~W} / \mathrm{m}^{2}$. Figure- 8 shows the different irradiance values of solar partial shaded photovoltaic array for cases 1 to 14 .

\section{MODELING AND SIMULATION OF REARRANGEMENT OF MODULES-BASED TCT CONFIGURATIONS:}

\subsection{Rearrangement of modules in 6x6 TCT PV Array}

The Photovoltaic modules in conventional TCT configurations are arranged in row and column wise for a 6x6 size array as shown in figure-9(a). The numbers 11 indicates $1^{\text {st }}$ row and $1^{\text {st }}$ column, 12 indicates $1^{\text {st }}$ row and $2^{\text {nd }}$ column etc., In SP and TCT, Optimal TCT configurations the modules in an array are doesn't change the positions whereas in remaining configurations the position of modules is rearranged based on number puzzle pattern. In this rearrangement modules-based configurations the modules in every column, row is changed to other column or rows in entire $6 \times 6$ size array depends on type of puzzle used. The rearrangement of modules is based on the puzzle analysis there are mainly proposed optimal TCT, modified TCT, new rearranged TCT, Zig-zag TCT, modified magic square TCT, half reconfigure TCT, full reconfigure TCT, Tom-tom TCT, new diagonal TCT and Ken-Do-Ku puzzle type TCT array-based method of repositioning of modules in an array [8-10]. In this method, only modules are rearranged in a different rows or columns without altering the electrical connection of PV configurations. So, the shade will be dispersed to a new row or column in array. It improves the performance of photovoltaic array compared to other conventional configurations without altering the module to module connections of array configuration. In this rearrangement-based configuration, the performance will be improved but it requires more wires for repositioning of modules to a new row or column in an array. It leads to wiring losses and increase the installation cost of the solar plant. The proposed rearrangement of modules based on puzzle pattern in new re-arranged TCT configuration are shown in figure-9. Similar way rearranged the modules to optimal location based on puzzle pattern for remaining array configurations.

In S-P configurations, strings (series connected modules) are connected in parallel as shown in figure-5(c).

In TCT type, all modules are connected with ties as shown in figure-5(d). In optimal TCT, interconnections are connected based on location of number of shaded modules in an array. In modified TCT type, $1^{\text {st }}$ column are remains same and $2^{\text {nd }}$, $3^{\text {rd }}, 4^{\text {th }}, 5^{\text {th }}, 6^{\text {th }}$ column modules are changed their positions as shown in figure- 10 .

In new re-arranged TCT type, $1^{\text {st }}$ column is unchanged and remaining all column modules are changed their position. In zigzag type, all modules are placed in zig-zag type as shown in figure-10. In modified MS type, magic square pattern is rearranged to new optimal location as shown in figure-10. In half re-configure type $1^{\text {st }}, 3^{\text {rd }}$ and $5^{\text {th }}$ column modules are changed their positions and $2^{\text {nd }}, 4^{\text {th }}, 6^{\text {th }}$ column modules are un changed their positions. Full reconfigure type, all shaded modules in array are changed to new positions within same column or rows. In Tom-Tom, Kendoku type, the modules in an array are arranged based on puzzle pattern arrangement as shown in figure-10. In new diagonal based TCT type, Modules in $1^{\text {st }}$ row and $6^{\text {th }}$ row are changed to cross diagonal type as shown in figure- 10 .

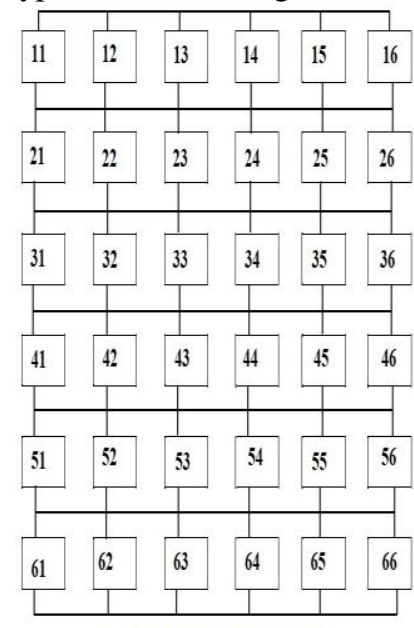

(a) 6r6 TCT PV Array Confifuration

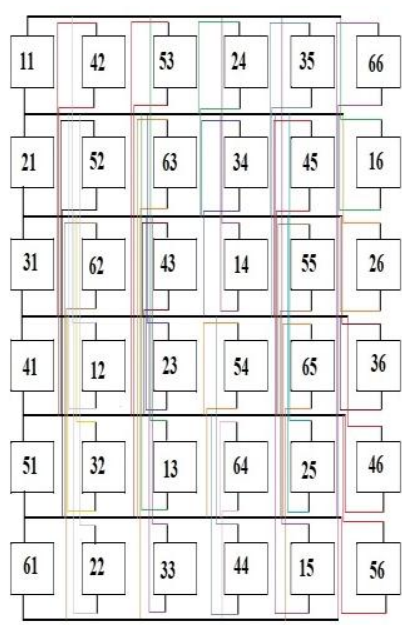

(b) 6r6 Vew Re-arranged TCT PV Array Configuration

Figure-9: Proposed Re-arrangement of TCT configurations

Published By: 
A Novel T-C-T Solar Photovoltaic Array Configurations using Rearrangement of PV Modules with Shade Dispersion Technique for Enhancing the Array Power

\begin{tabular}{|c|c|c|c|c|c|c|c|c|c|c|c|}
\hline & \multicolumn{4}{|c|}{ Seripe-Parallel } & \multicolumn{3}{|c|}{ Total Cross Tied (ICT) } & \multicolumn{3}{|c|}{ Optimal ICT } & IIodified TCT \\
\hline & & 13 & 14 & & & 12 & & 1213 & 4 & & $\begin{array}{lllllll}11 & 62 & 53 & 44 & 35 & 26 \\
\end{array}$ \\
\hline & & & & & & & & & & & $\begin{array}{lllllll}21 & 12 & 63 & 54 & 45 & 36\end{array}$ \\
\hline & & & & & & & & & & & $\begin{array}{llllll}31 & 22 & 13 & 64 & 55 & 46\end{array}$ \\
\hline & & & & & & & & & & & \begin{tabular}{|l|l|l|l|}
41 & 32 & 23 & 14
\end{tabular} \\
\hline & & 53 & & & & & & 5253 & & & \begin{tabular}{|llllll}
51 & 42 & 33 & 24 & 15
\end{tabular} \\
\hline & & & & & & & & & & & \\
\hline
\end{tabular}

\begin{tabular}{|c|c|c|c|c|c|c|c|c|c|c|c|c|c|c|c|c|c|c|c|c|c|}
\hline & & & & & \multicolumn{6}{|c|}{ Zig Zag-TCT } & \multicolumn{6}{|c|}{ Modified Magic Square TCT } & & \multicolumn{4}{|c|}{ HalfReconfigure TCT } \\
\hline & 42. & 53. & & & & & 42 & 3 & 15 & & & & & 646 & & 2 & & & \begin{tabular}{l|l}
12 & 1 \\
\end{tabular} & & \\
\hline & 52 & 63 & 34 & & & 1 & 12 & & 55 & 36 & 51 & & & & & 55 & & & 22 & & \\
\hline 31 & 62 & 43 & 4 & 26 & & 1 & 62 & & 35 & 56 & 46 & & & & & 23 & & & 32 & & \\
\hline 41 & 12 & 23 & 646 & & & 1 & 32 & & 65 & 26 & 36 & & ? & 43 & 4 & 54 & & & 424 & & \\
\hline 51 & 32 & 13 & 44 & & & 1 & 52 & & 13 & 46 & 26 & & ? & & & 52 & & & 525 & & \\
\hline 61 & 22 & 33 & 14 & 56 & & 1 & 22 & & 45 & & 61 & & & & & 626 & & & 626 & & \\
\hline
\end{tabular}

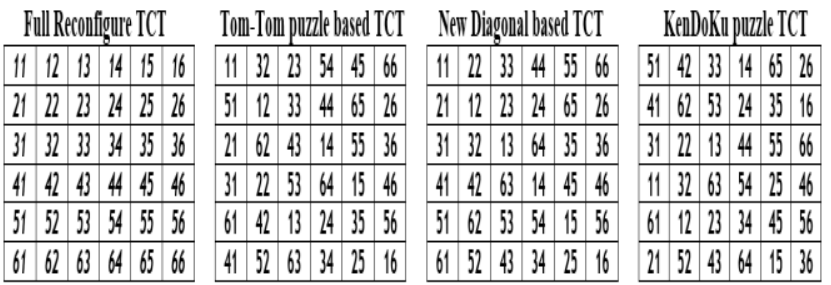

Figure-10: Proposed new TCT photovoltaic array re-configurations based on puzzle pattern

5.2 Shade dispersion analysis of puzzle based modified TCT Configuration:
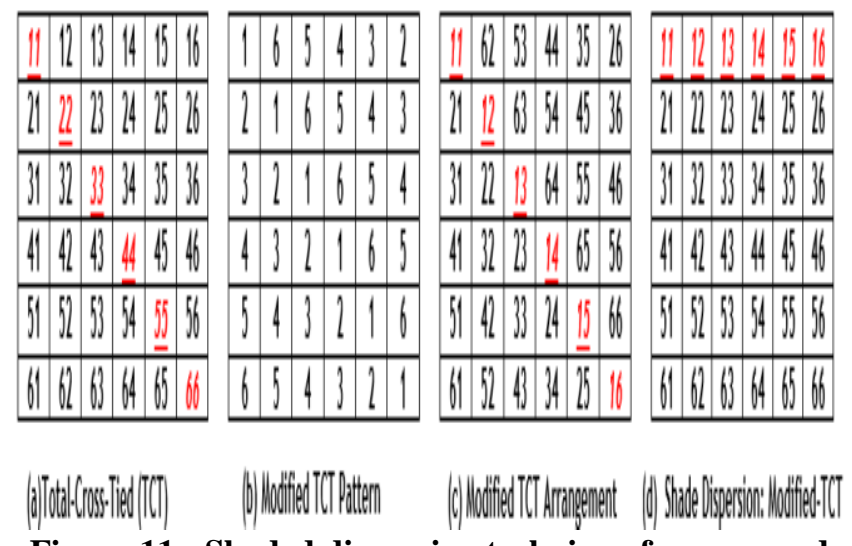

\section{Figure-11: Shaded dispersion technique for proposed modified TCT configuration}

The figure-11 shows the shade dispersion analysis for the proposed puzzle based TCT configuration. For a $6 \times 6$ size TCT PV array consists of 6 rows and 6 columns of modules as shown figure-9(a). In this method, positioning of modules in optimal location based on puzzle patterns but its electrical connections are same as TCT configuration. The modules arrangement in modified TCT pattern are shown in figure-9(b). In this pattern, $1^{\text {st }}$ column modules are remains unchanged and remaining five column modules are changed their positions as shown in figure-9(c). The diagonal modules in the TCT configuration are shaded, the modules are repositioning to new optimal location in same column by rearrangement of modules based on puzzle number analysis as shown in figure-9(c). In this arrangement, the shaded modules are changed their positions and shade will be dispersed to a new location in array configuration as shown in figure-9(d) shade dispersion with modified TCT configuration. By this shade dispersion technique, without altering the electrical connections the shade will be dispersion by simply re-positioning of existing modules in an array and it will improve the array power as compared to conventional TCT configuration [10-12]. The losses due to shading effect on SPV array topologies are shown in figure-12

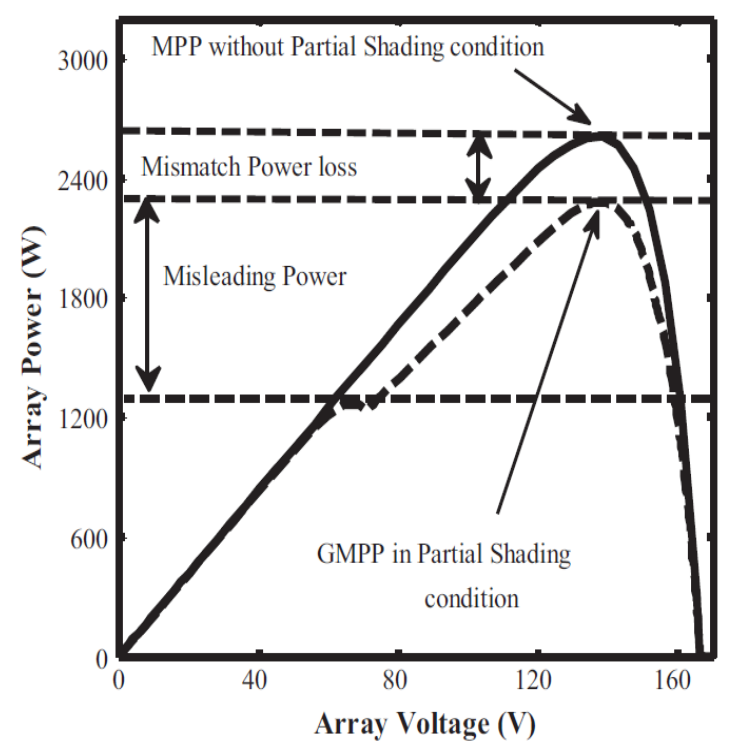

Figure-12: Different shading losses in PV Array

\subsection{Performance of Re-arrangement modules based TCT array Configurations:}

The performance of Re-arrangement of modules based TCT configuration is better as compared to SP, BL, HC type of conventional configurations with respect to global maximum power, power loss, Fill-Factor [8-9, 15-16]. In this paper, new type of TCT array configurations are developed based on puzzle patterns and investigated the performance of these configurations. In the proposed puzzle-based shade dispersion arrangement of modules in an array distribute the shaded modules to optimal location and enhance the array power of different configurations. The SPV array current depends on solar irradiation $(\mathrm{G})$ given as,

$I=\left(\frac{G}{G_{S T C}}\right) \times I_{m}$

Where $\mathrm{I}_{\mathrm{m}}$ is maximum module current at STC (irradiation of $1000 \mathrm{~W} / \mathrm{m}^{2}$ and temperature of $25^{\circ} \mathrm{C}$ ). The Solar PV array voltage is given as,

$V=\sum_{i=1}^{6} V_{m i}$

Where $\mathrm{V}_{\mathrm{mi}}$ is the $\mathrm{i}^{\text {th }}$ row of array voltage.

This section describes the comprehensive analysis of SP, TCT, proposed optimal and puzzle-based rearrangement TCT array configurations [6-17] under one un shaded case- $U$ and 14 different proposed partial shading cases (cases 1 to 14). 
The proposed optimal interconnection method is applied to any size of PV system and improves the array power, requires minimum number of ties, less shading losses as compared to SP configuration and rearranged TCT configurations. The implementation of proposed optimal method is simple because it doesn't require any switches or sensors [10-12].

The interconnections or ties between modules are a, b, c, d, e, f, g, h, i, j, k, l, m, n, o, p, q, r, s, t, u, v, w, x and y are shown in figure-5. For SP configurations there is no ties are required and in puzzle based rearranged TCT array configurations total 25 ties are required among modules and in case of proposed optimal configuration only a smaller number of interconnections or ties required depends upon shading pattern. In this proposed optimal method, the mismatch losses given in equation (4) are reduced as compared to series-parallel (SP) configuration and number of ties are less as compared to TCT SPV array configuration. The global maximum power is improved compared to SP and less than rearranged puzzle based TCT array configurations. Due to optimal ties the wiring required for installation of PV system and wiring losses are reduced [14-17].

Mismatch power loss $\boldsymbol{P}_{\text {mmloss }}(\boldsymbol{W})=\boldsymbol{P}_{m u}-\boldsymbol{P}_{\text {mpsc }}$

(4)

$$
\begin{aligned}
& \% \text { Power loss }=\frac{r_{m u}-P_{m p s c}}{P_{m u}} \times 100 \\
& \text { Fill-Factor }=\frac{V_{m p p^{*}} I_{m y p}}{V_{o c} I_{s c}} \\
& \text { Efficiency, } \eta=\frac{V_{m p} * I_{m p}}{P_{t n}}
\end{aligned}
$$

Where $\mathrm{P}_{\mathrm{in}}=$ Number of module $\mathbf{x}$ Area of Module

Area of module $=1952 \times 982 \mathrm{~mm}$ (given in data sheet of Vikram solar ELDORA 270W Module)

Where $\boldsymbol{P}_{m u}$ is global maximum peak power under unshaded case of full irradiation $1000 \mathrm{~W} / \mathrm{m}^{2}$ and $\boldsymbol{P}_{\text {mpse }}$ is global maximum power under different shading cases. $\mathrm{V}_{\mathrm{mp}}, \mathrm{I}_{\mathrm{mp}}, \mathrm{V}_{\mathrm{oc}}$, $I_{\mathrm{sc}}$ are the voltage at maximum peak power (mpp), current at mpp, open circuit voltage, short circuit currents of module respectively.

\subsection{Wiring Losses in PV array configurations}

The repositioning of modules to optimal location within an array increases the length of wires required for interconnection of modules and results the wire resistance is increased, causes a wire loss and also increases voltage drop in an array. The extra lengths of wires required for rearrangement of every module within an array. It increases the wiring losses in a rearrangement based TCT array configurations as compared to optimal interconnections of TCT configuration in proposed different partial shading conditions. If the connections between modules in an array are less, the wiring requirement for installations of PV system is reduced but in TCT array configuration the number of ties or interconnections among modules are more so the wiring requirement is more. In TCT type of SPV array topologies the cost of the installation for PV system is increased and also wiring losses are more due to more length of wires used for interconnection of modules in the PV array.

\section{RESULTS AND DISCUSSION}

The output P-V (Power-Voltage) characteristics of SP, rearrangement of modules based on puzzle pattern TCT array configurations and proposed optimal topologies under 14 shading cases and one un-shaded case- $U$ are shown in figures- 13 to 24 . The obtained global maximum output array power of SP, rearranged TCT and proposed optimal TCT topologies are shown in figures-25. Under un-shaded case- $U$, the power obtained in SP, rearranged modules based TCT and proposed optimal configurations are equal i.e., $9620 \mathrm{~W}$ and power changes in different shading cases shown in figure-6. The array global maximum peak power (GMMP) and mismatch or shading losses, fill-factor, efficiency of proposed TCT array configurations under 14 different proposed partial shading cases (case:1-14) are shown in figure- 6 are tabulated in Table-5.

From the simulation results it can be summarized that,

* In partial shading case-1: New re-arranged TCT, modified MS-TCT, Tom-Tom puzzle based TCT, New X-diagonal TCT and Kendoku puzzle type TCT has maximum global peak power of $8834 \mathrm{~W}$.

* In partial shading case-2: All PV configurations has maximum global peak power of $8834 \mathrm{~W}$.

* In partial shading case-3: Zig-Zag type TCT and Kendoku puzzle based TCT has maximum power of $7097 \mathrm{~W}$.

* In partial shading case-4: TCT, proposed optimal TCT, modified MS, half and full re-configure TCT configurations has maximum power of $8834 \mathrm{~W}$.

* In partial shading case-5: New rearranged TCT and modified MS-TCT configurations has maximum power of $8916 \mathrm{~W}$.

* In partial shading case-6: New re-arranged TCT, Zig-zag type TCT, modified MS-TCT, Kendoku, half and full re-configure TCT configurations have maximum power of $7790 \mathrm{~W}$.

* In partial shading case-7: New re-arranged TCT, Zig-zag type TCT, puzzle-based Tom-Tom and Kendoku type of configurations has maximum power of $7618 \mathrm{~W}$.

* In partial shading case-8: New re-arranged TCT and half reconfigure TCT configurations has maximum power of $6480 \mathrm{~W}$.

* In partial shading case-9: Half re-configure type of TCT configuration has maximum power of $7422 \mathrm{~W}$.

* In partial shading case-10: New re-arranged TCT type of configuration has maximum power of $7313 \mathrm{~W}$.

* In partial shading case-11: all configurations except SP, optimal TCT and modified TCT has maximum global power of $5704 \mathrm{~W}$.

* In partial shading case-12: all configurations except SP, new rearranged, zig-zag, tom-tom, new diagonal TCT con figuration s has maximum power of $8049 \mathrm{~W}$.

* In partial shading case-13: all configurations except SP, optimal TCT and modified TCT has maximum global power of $9352 \mathrm{~W}$. 
* In partial shading case-14: New re-arranged TCT, modified MS and Tom-Tom puzzle based TCT configurations has maximum power of $6716 \mathrm{~W}$.

* Under partial shading conditions, rearrangement based Total- Cross-Tied (TCT) configurations has improved results than conventional array topologies.

* The proposed optimal array TCT configuration requires a smaller number of ties among array modules and getting more power as compared to Series-parallel array configuration but lesser output power as compared to re-arranged based TCT array configurations.

* Depending upon shading pattern occurs in an array module, the number of interconnections is increase or decrease. In proposed method of configuration, the ties or interconnection for connection of modules in an array are based on shading pattern in the array.

* For considering wiring losses in TCT and rearranged based TCT configurations due to extra requirement of wiring for installation of PV system, the proposed optimal TCT array configuration has the better results compared to other rearranged based TCT configurations.

Among all 14 proposed partial shading cases, it can be concluded that new re-arranged type of puzzle pattern based TCT array configuration has highest GMPP least mismatch power losses as compared to other type of TCT solar array configurations are given in Taale-5.

\section{Table-5: The performance of different proposed PV} array configurations

\begin{tabular}{|c|c|c|c|c|c|c|c|c|c|c|c|c|c|c|c|}
\hline \multirow{2}{*}{$\begin{array}{l}\text { Configun- } \\
\text { tions }\end{array}$} & \multirow[t]{2}{*}{ Pramters } & \multicolumn{14}{|c|}{ Cass } \\
\hline & & 1 & $!$ & 3 & t & $j$ & 6 & 1 & 8 & 9 & 10 & 11 & 12 & 13 & It \\
\hline \multirow{5}{*}{ Thifom } & $P_{\text {Ganp }}$ (II) & 9620 & 9620 & 9620 & 9620 & 9620 & 9600 & 9600 & 9600 & 9600 & 9600 & 9600 & 9600 & 9600 & 9600 \\
\hline & $P_{\text {malus }}$ (II) & 0 & 0 & 0 & 0 & 0 & 0 & 0 & 0 & 0 & 0 & 0 & 0 & 0 & 0 \\
\hline & YPPorer Loss & 0 & 0 & 0 & 0 & 0 & 0 & 0 & 0 & 0 & 0 & 0 & 0 & 0 & 0 \\
\hline & Filfirtor" & 0.743 & 0,743 & 0,743 & 0.748 & 0.743 & 0.743 & 0,743 & 0,743 & 0,743 & 0.743 & 0.743 & 0.743 & 0.743 & 0.743 \\
\hline & 1 & 140 & 140 & 140 & 140 & 140 & 140 & 140 & 140 & 140 & 140 & 140 & 140 & 140 & 140 \\
\hline \multirow{5}{*}{ SP } & $P_{\text {Gan }}$ (II) & 7974 & 8834 & 5550 & 7974 & 8123 & 7339 & 541 & 5154 & 6617 & 5346 & 4113 & 6328 & 8869 & 5990 \\
\hline & $P_{\text {andes }}$ (II) & 16046 & 786 & 400 & 1646 & 1497 & 2881 & 4179 & 4666 & 303 & 4274 & 5507 & 3292 & 751 & 430 \\
\hline & YPorer Loss & 17.11 & 8.17 & 42.3 & 17,11 & 1556 & 23.71 & 43.4 & 46.42 & 31.21 & 4.42 & 57.24 & 34.21 & 7.80 & 46.05 \\
\hline & Fillfactor & 0.619 & 0.74 & 0.43. & 0.619 & 0.627 & 0.567 & 0.424 & 0.485 & 0.511 & 0.50 & 0.341 & 0.493 & 0.685 & 0.439 \\
\hline & $\|$ & 12.57 & 13.94 & 10.14 & 12.57 & 1266. & 12.7 & 9.76 & 11.17 & 12.29 & 10.69 & 9.77 & 10.97 & 13.0 & 10.59 \\
\hline \multirow{5}{*}{ ICI } & $P_{\text {Cand }}$ (II) & 7974 & 8834 & 7082 & 8834 & 8558 & 7687 & 5725 & 5285 & 6778 & 5433 & 5704 & 8049 & 9352 & 5510 \\
\hline & $P_{\text {andes }}$ (II) & 1646 & 786 & 2538 & 786 & 1062 & 1933 & 3895 & 4335 & 2842 & 4.87 & 3916 & 1571 & 268 & 4110 \\
\hline & YPorter Loss & 17,11 & 8.17 & 26.38 & 8.17 & 11.03 & 20.10 & 40.48 & 45,06 & 20.54 & 43.52 & 40.70 & 16.33 & 2.78 & 42,72 \\
\hline & Fillfactor & 0.619 & 0.747 & 0,002 & 0747 & 0.663 & 0.598 & 0.47 & 0.498 & 0.53 & 0.511 & 0.675 & 0.752 & 0.7212 & 0.472 \\
\hline & 1 & 1258 & 13.94 & 12.94 & 1399 & 1330 & 13.34 & 10,28 & 11.47 & 1260 & 10.88 & 13.56 & 13.97 & 13.72 & 11.25 \\
\hline \multirow{5}{*}{ a. } & $P_{\text {Pand }}$ (II) & 7974 & 8834 & 7022 & 8834 & 8257 & 7993 & 544 & 5213 & 6752 & 5410 & 4996 & 8049 & 8990 & 5294 \\
\hline & Pulase $($ II) & 1646 & 786 & 2578 & 786 & 1363 & 2127 & 4179 & 407 & 2868 & 4210 & 5424 & 1571 & 630 & 4326 \\
\hline & YPorrer Loss & 17.11 & 8.17 & 26.79 & 8.17 & 14.16 & 22.11 & 43.4 & 45.81 & 29.81 & 43.76 & 56.38 & 16.33 & 6.54 & 4.96 \\
\hline & Fillfactor & 0.619 & 0.744 & 0.598 & 0.746 & 0.638 & 0.579 & 0.424 & 0.49 & 0.566 & 0.506 & 0.355 & 0.752 & 0.694 & 0.45 \\
\hline & $\|$ & 1258 & 13.94 & 12.87 & 13,94 & 1283 & 13.0 & 9.77 & 11.31 & 12.56 & 10.83 & 9.98 & 13.97 & 13.19 & 10.81 \\
\hline \multirow[t]{5}{*}{ t. } & $P_{\text {and }}$ (II) & 7974 & 8834 & 6784 & 8524 & 8522 & 7643 & 5615 & 5659 & 6749 & 5424 & 5225 & 8049 & 960 & 5,30 \\
\hline & Palases (II) & 1646 & 786 & 2836 & 1096 & 1098 & 1977 & 4005 & 4361 & 2871 & 4996 & 4395 & 1571 & 360 & 499 \\
\hline & yPorere Loss & 17:11 & 8.17 & 29.48 & 11.40 & 11.41 & 20.55 & 41.63 & 45.33 & 20.84 & 43.61 & 45.68 & 16.33 & 3.14 & 43.55 \\
\hline & Fillfactor & 0.619 & 0.746 & 0.577 & 0.66. & 0.659 & 0.593 & 0.438 & 0.495 & 0.527 & 0.51 & 0.524 & 0.75 & 0.715 & 0.464 \\
\hline & $\|$ & 12.58 & 13.94 & 12.39 & 13,45 & 13.25 & 13.27 & 10,08 & 11.41 & 12.55 & 10.86 & 12,42 & 13.97 & 13.58 & 11.09 \\
\hline
\end{tabular}

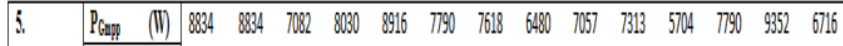

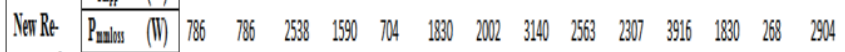
$\begin{array}{llllllllllllllll}\text { annaged } & \text { 9.Porer Loss } & 8.17 & 8.17 & 26.38 & 16.52 & 7.31 & 19.02 & 20.81 & 32.64 & 26.64 & 23.98 & 40.70 & 19.02 & 2.778 & 30.18\end{array}$ \begin{tabular}{llllllllllllllll}
\hline ICT & Fillfator & 0.747 & 0.747 & 0.604 & 0.623 & 0.691 & 0.661 & 0.711 & 0.762 & 0.661 & 0.685 & 0.675 & 0.662 & 0.722 & 0.70
\end{tabular} $\begin{array}{lllllllllllllll}113 & 13.94 & 13.94 & 12.94 & 12.67 & 13.86 & 13.52 & 13.68 & 140 & 13.12 & 14.6 & 13.56 & 13.52 & 13.72 & 13.71\end{array}$

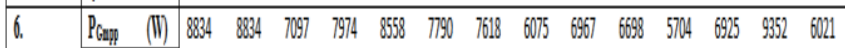

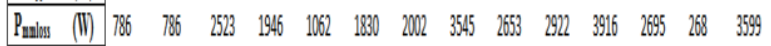

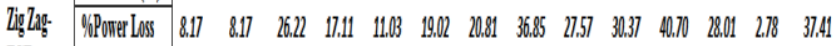
$\begin{array}{llllllllllllllll}\text { ICT } & \text { Filffator } & 0.747 & 0.747 & 0.665 & 0.619 & 0.663 & 0.662 & 0.712 & 0.635 & 0.651 & 0.629 & 0.675 & 0.54 & 0.722 & 0.63\end{array}$ $\begin{array}{llllllllllllllll}113.94 & 13.94 & 12.97 & 12.58 & 13.30 & 13.52 & 13.68 & 13.18 & 12.36 & 13.41 & 13.56 & 12.02 & 13.72 & 12.29\end{array}$ 7. $\quad$\begin{tabular}{llllllllllllllll}
\hline Gang & (II) & 7899 & 8834 & 7082 & 8834 & 8916 & 7790 & 7550 & 6157 & 6778 & 5433 & 5704 & 8049 & 9352 & 6716
\end{tabular}

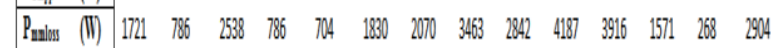
$\begin{array}{llllllllllllllll}\text { Mlodified } & \text { Y.Porer Loss } & 17.88 & 8.17 & 26.38 & 8.17 & 731 & 19.02 & 21.51 & 36.0 & 2.54 & 4.52 & 40.70 & 16.33 & 2.78 & 30.18\end{array}$

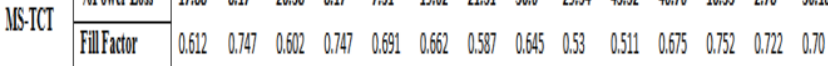
\begin{tabular}{llllllllllllllll}
\hline 1 & 12.46 & 13.94 & 12.94 & 13.94 & 13.86 & 13.52 & 13.56 & 13.36 & 12.60 & 10.88 & 13.56 & 13.97 & 19.72 & 13.71
\end{tabular}

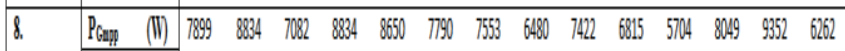

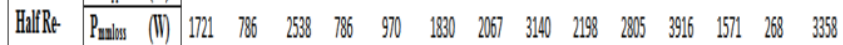

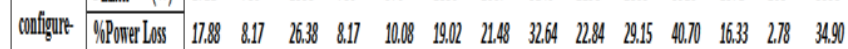
$\begin{array}{llllllllllllllllll}\text { ICT } & \text { Fulfintor } & 0.613 & 0.747 & 0.60 & 0.747 & 0.67 & 0.662 & 0.642 & 0.762 & 0.695 & 0.71 & 0.675 & 0.752 & 0.722 & 0.655\end{array}$ $\begin{array}{lllllllllllllll}112.46 & 13.94 & 12.94 & 13.94 & 13.4 & 13.52 & 13.56 & 14.06 & 13.30 & 13.65 & 13.56 & 13.97 & 13.72 & 12.79\end{array}$

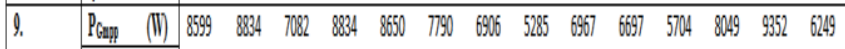

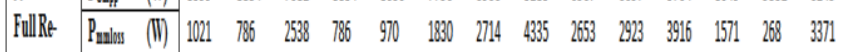
$\begin{array}{llllllllllllllllll}\text { configurt } & \text { MPorer Loss } & 10.61 & 8.17 & 26.38 & 8.17 & 10.08 & 19.02 & 28.21 & 45.06 & 27.57 & 30.38 & 40.70 & 16.33 & 2.78 & 35.02\end{array}$ $\begin{array}{lllllllllllllllllll}\text { ICT } & \text { Fillfator } & 0.667 & 0.747 & 0.60 & 0.747 & 0.671 & 0.662 & 0.537 & 0.499 & 0.65 & 0.629 & 0.675 & 0.752 & 0.723 & 0.583\end{array}$ \begin{tabular}{lllllllllllllllll}
\hline 1 & 13.57 & 13.94 & 12.94 & 13.94 & 13.4 & 13.52 & 12.40 & 11.47 & 12.96 & 13.4 & 13.56 & 13.97 & 13.72 & 12.76
\end{tabular}

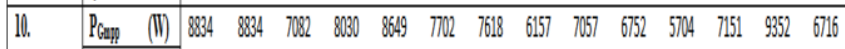

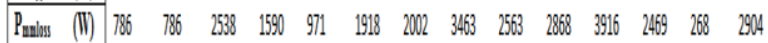

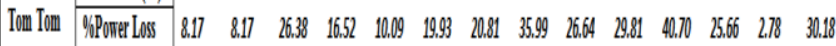

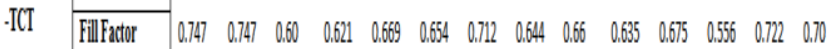
\begin{tabular}{llllllllllllllll}
\hline$\pi$ & 13.94 & 13.94 & 12.94 & 12.67 & 13.44 & 13.37 & 13.68 & 13.36 & 13.12 & 13.52 & 13.56 & 12.41 & 13.72 & 13.71 \\
\hline
\end{tabular}

\begin{tabular}{lllllllllllllllll}
\hline 11. & Paun & (II) & 8834 & 8834 & 7513 & 7974 & 8558 & 7702 & 6416 & 6011 & 696 & 6698 & 5704 & 6328 & 9352 & 5768
\end{tabular}

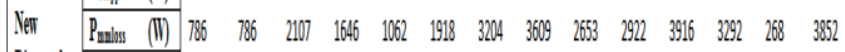

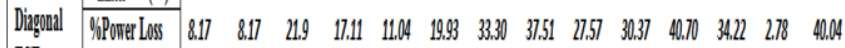
$\begin{array}{lllllllllllllllll}\text { ICT } & \text { FulfFator } & 0.747 & 0.747 & 0.70 & 0.619 & 0.663 & 0.654 & 0.546 & 0.628 & 0.651 & 0.629 & 0.675 & 0.493 & 0.722 & 0.543\end{array}$ $\begin{array}{lllllllllllllll}13.94 & 13.94 & 13,73 & 12.58 & 13.30 & 13.37 & 11.52 & 13.04 & 12.25 & 13.41 & 13.56 & 10.98 & 13.72 & 11.78\end{array}$

\begin{tabular}{l|llllllllllllllll}
\hline 12. & Paun & (II) & 8834 & 8834 & 7097 & 8564 & 8650 & 7790 & 76.8 & 6157 & 7057 & 6752 & 5704 & 849 & 9552 & 6224
\end{tabular}

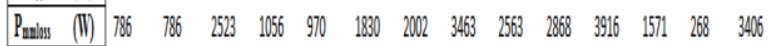

$\begin{array}{llllllllllllllll}\text { Ken-Dor } & \text { M.PPorer Los } & 8.17 & 8.17 & 26.22 & 10.97 & 10.08 & 19.02 & 20.81 & 35.99 & 26.64 & 29.81 & 40.70 & 16.33 & 2.78 & 35.40\end{array}$

$\begin{array}{lllllllllllllllll}\text { KII } & \text { Fullfator } & 0.747 & 0.747 & 0.664 & 0.665 & 0.671 & 0.662 & 0.712 & 0.645 & 0.661 & 0.634 & 0.674 & 0.752 & 0.723 & 0.584\end{array}$ \begin{tabular}{lllllllllllllll}
\hline 1 & 13.94 & 13.94 & 12.97 & 13.51 & 13.4 & 13.52 & 13.68 & 13.36 & 13.12 & 13.52 & 13.56 & 13.97 & 13.72 & 12.69
\end{tabular}

\subsection{Simulation Results:}

The output power P-V (Power-Voltage) characteristics of 6x6 size solar PV configurations for different cases are shown in below figures 10 to 21 . The global maximum peak powers for different configurations are shown in chart- 22 .

\section{a. Series(S)-Parallel (P) Configuration:}




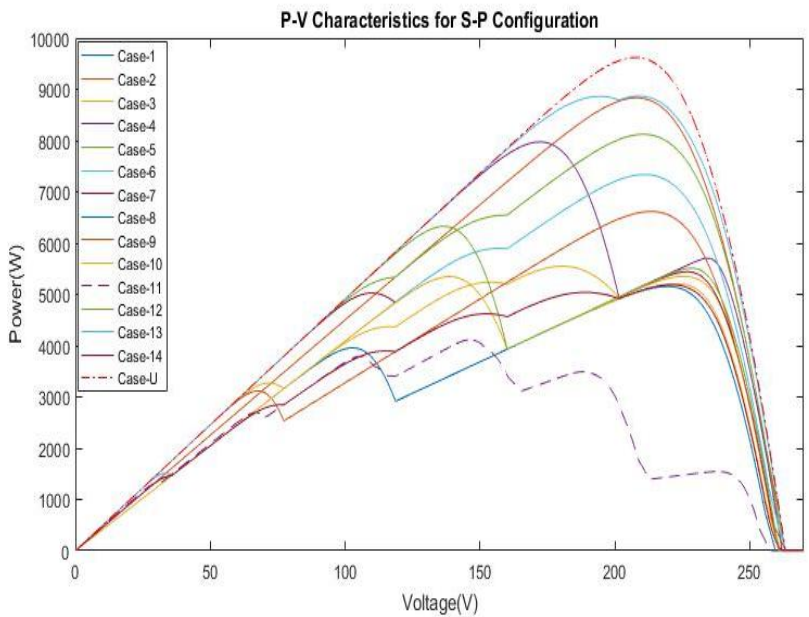

Figure-13. 6 × 6 S-P array configuration Output characteristics

b. Total (T)-Cross(C)-Tied (T) Configuration:

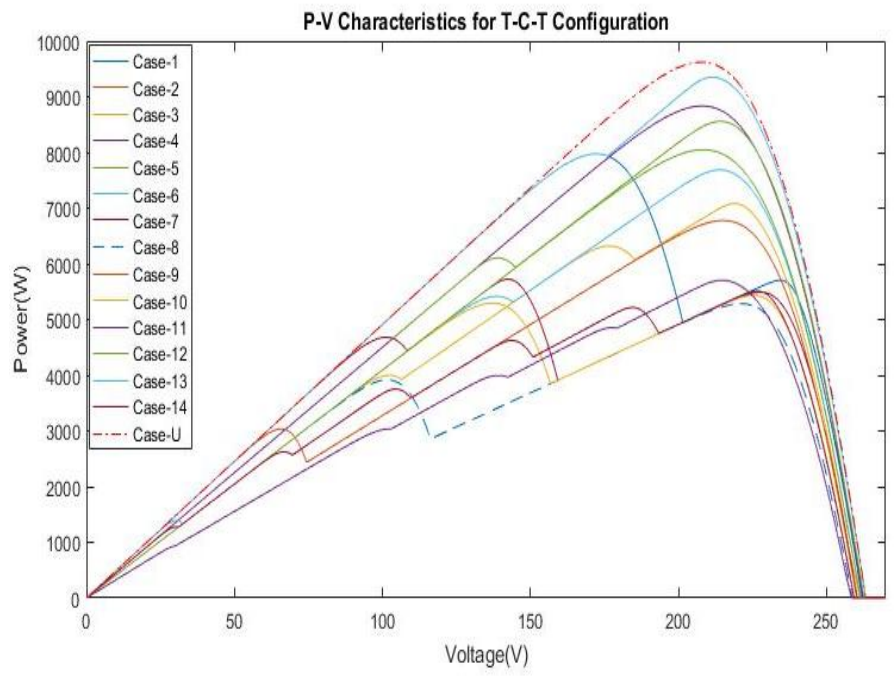

Figure-14. TCT topology Output characteristics

c. Proposed optimal TCT configuration:

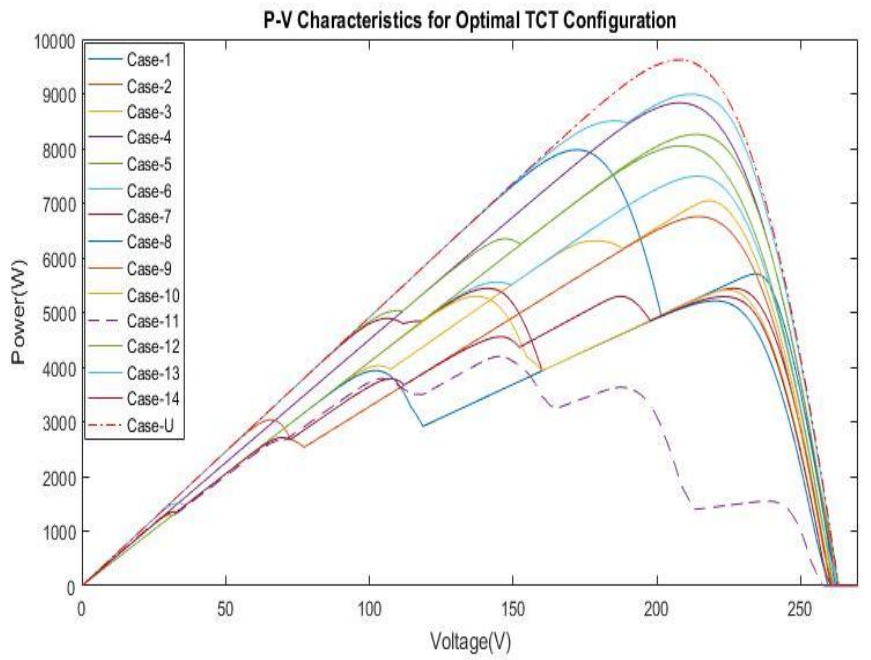

Figure-15. P-V characteristics for proposed optimal topology

d. Modified T-C-T configuration:

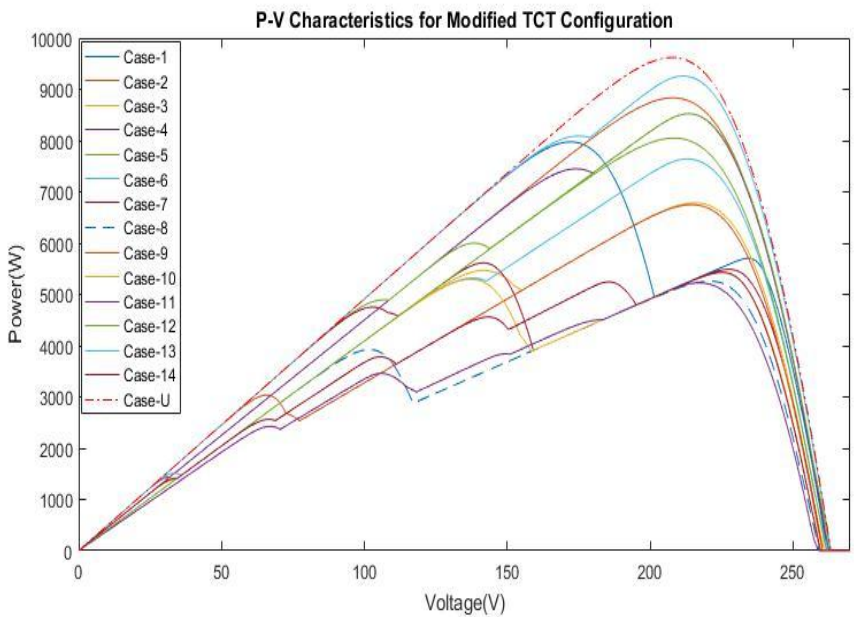

Figure-16. Modified-TCT configuration characteristics

e. New re-arranged TCT configuration:

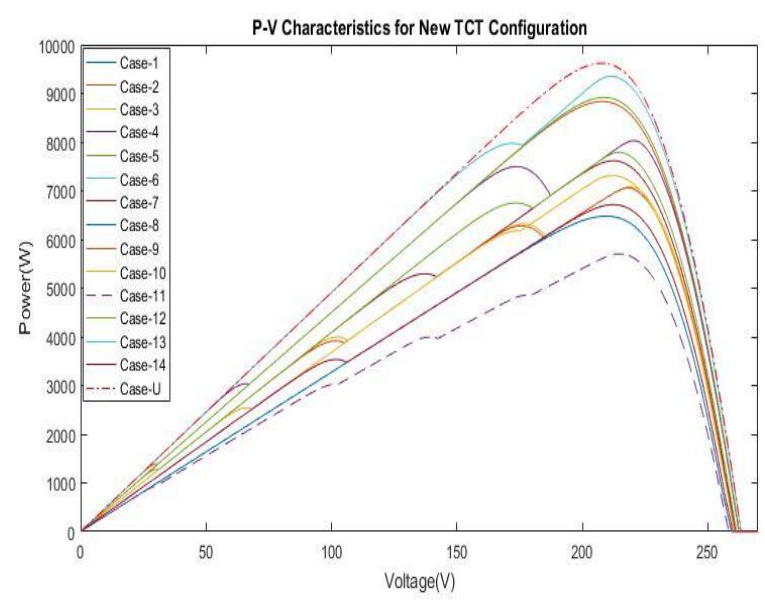

Figure-17. New TCT configuration characteristics

\section{f. Modified MS- TCT configuration:}

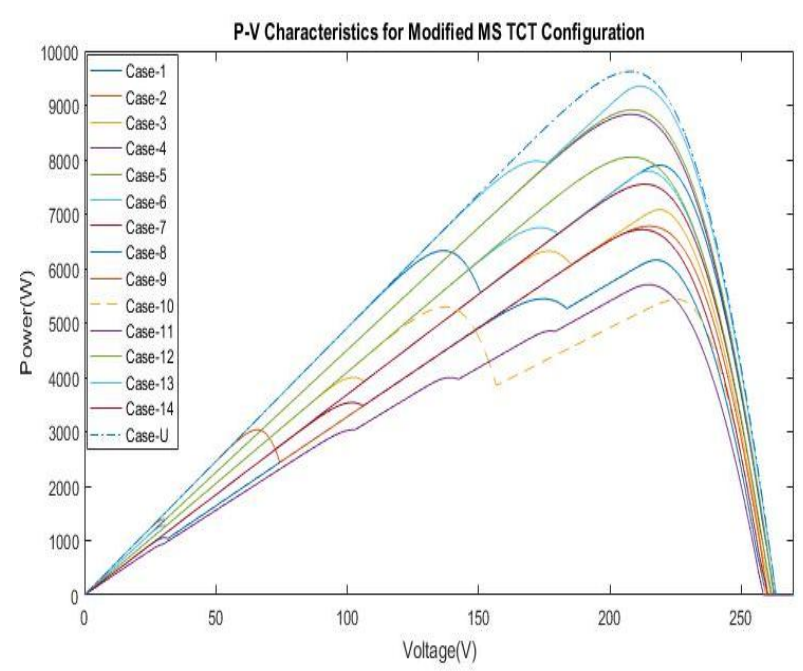

Figure-18. Modified MS-TCT topology characteristics g. Zig-Zag TCT configuration:

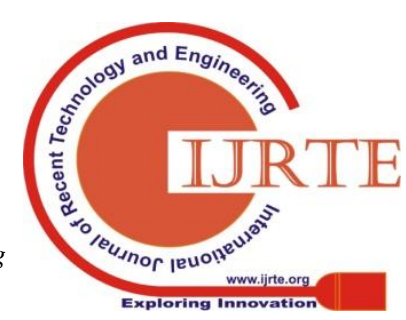


A Novel T-C-T Solar Photovoltaic Array Configurations using Rearrangement of PV Modules with Shade Dispersion Technique for Enhancing the Array Power

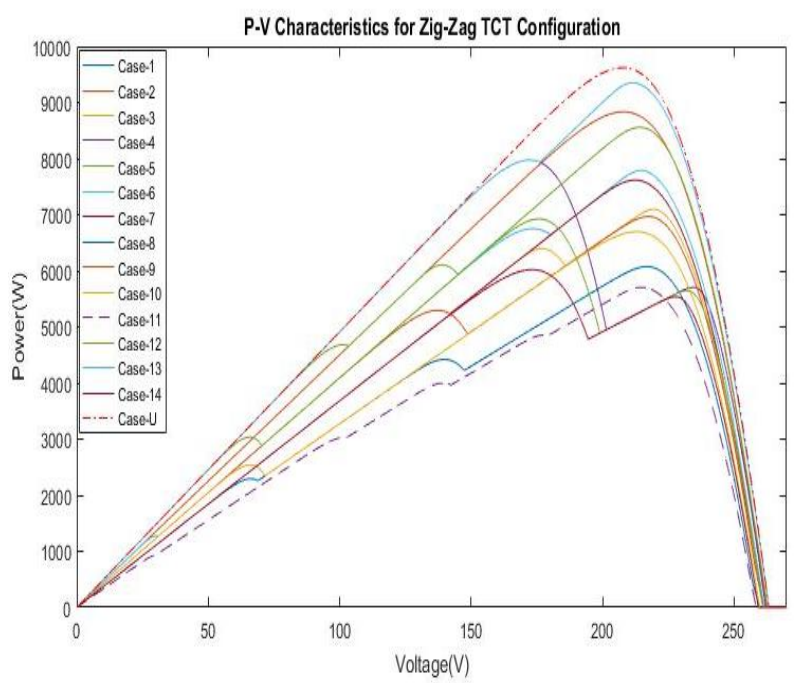

Figure-19. Zig-Zag TCT topology characteristics

h. Half Re-arrangement TCT configuration:

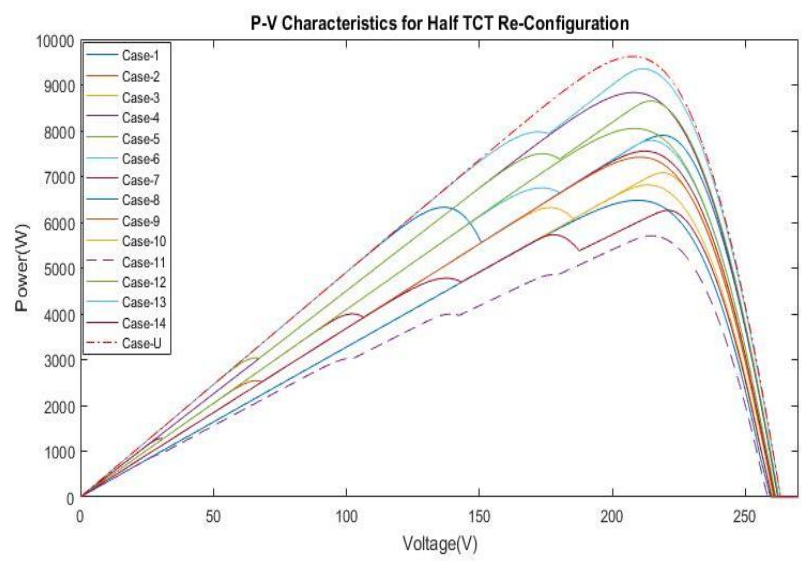

Figure-20. Half TCT Re-configuration characteristics

i. Full Re-arrangement TCT configuration:

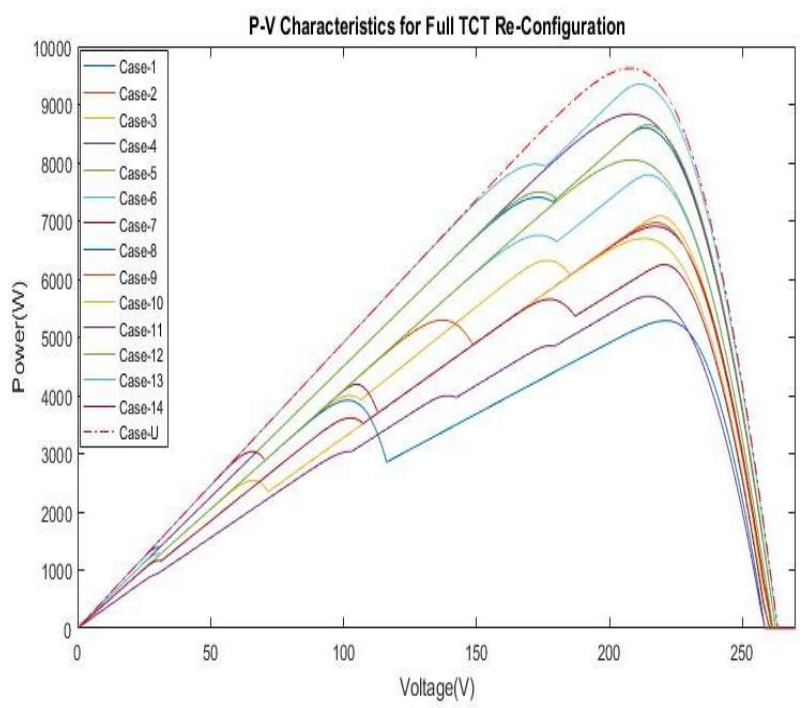

Figure-21. Full TCT Re-configuration characteristics j. New Tom-Tom based TCT configuration:

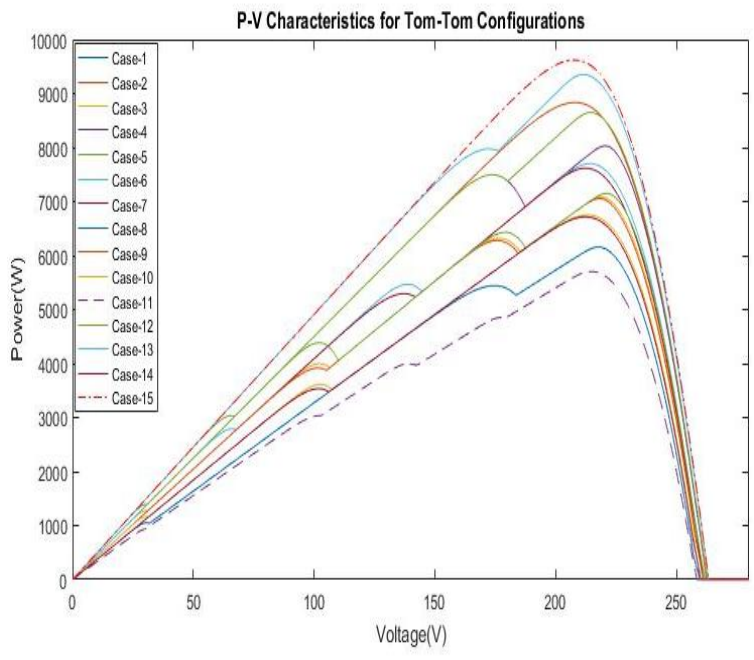

Figure-22. New Tom-Tom topology characteristics

k. Cross- Diagonal TCT configuration:

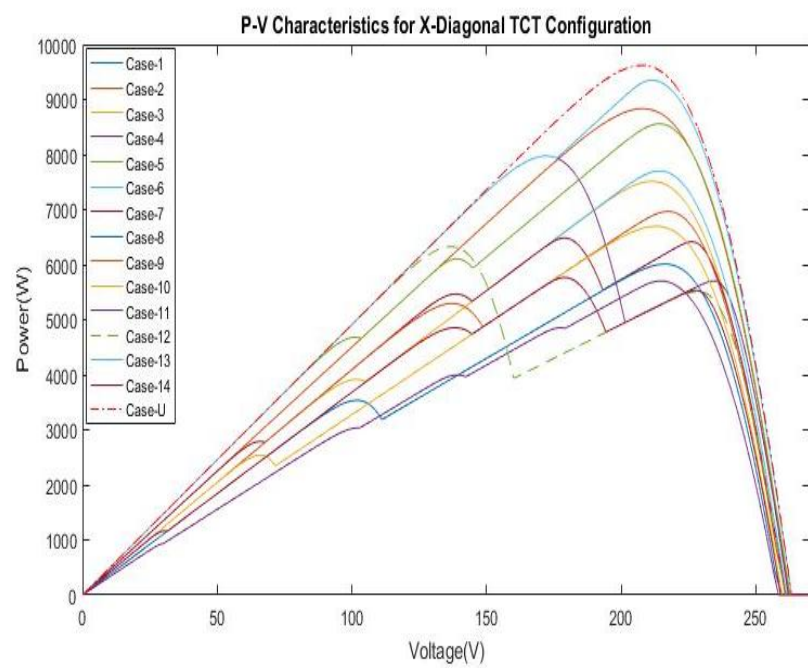

Figure-23. New diagonal configuration characteristics l. New Kendoku TCT configuration:

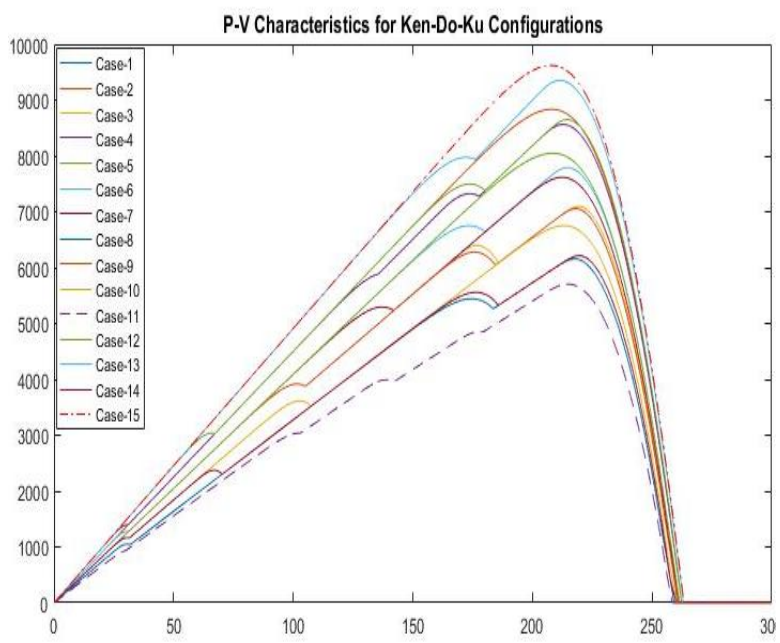

Figure-24. New Kendoko puzzle type topology characteristics

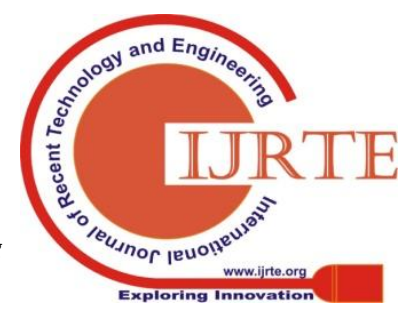




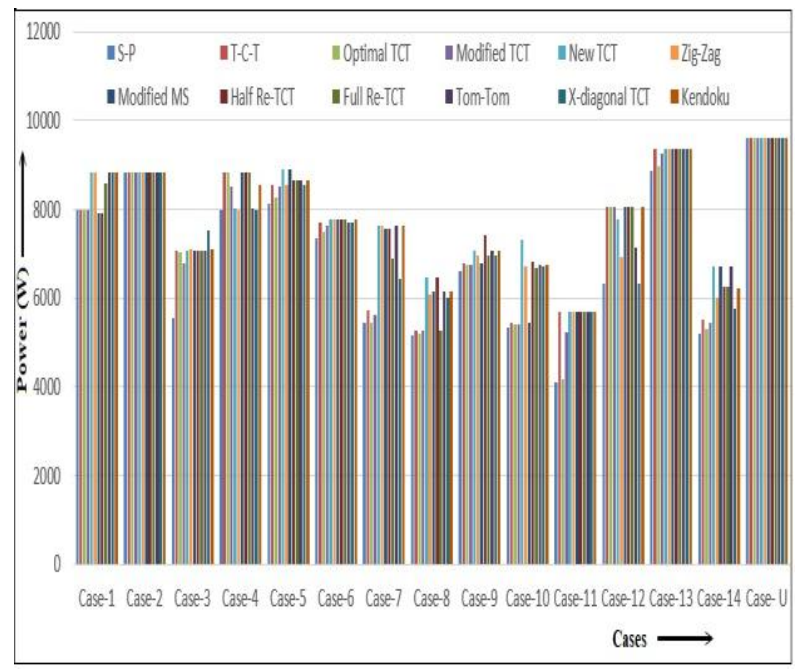

Figure-25: Maximum Powers for different Configurations

\section{CONCLUSIONS}

The rearrangement of array modules configurations based on puzzle pattern arrangements such as TCT, optimal TCT, modified TCT, new re-arranged TCT, Zig-Zag TCT, modified MS TCT, Half and Full re-configure TCT, Tom-Tom puzzle based TCT, new diagonal TCT, Ken-do-ku puzzle based TCT topologies and the proposed optimal TCT configuration are presented in this paper and compare the performance of each configuration with respect to global maximum peak power, Fill-factor, mismatch losses and efficiency under fourteen different partial shading cases and one un-shaded case. The optimal position of modules in different proposed TCT array configurations are developed by puzzle number based arrangement method with the help of re-positioning the modules but electrical connections are unchanged. The requirement of wires for interconnection among modules and wiring losses are more due to repositioning of modules to new optimal position in the array without altering the module to module interconnections in the SPV array configuration. The proposed optimal location method improves the performance of conventional TCT and re-arranged TCT array configurations and also minimize the number of ties, installation time and installation cost of photovoltaic system.

\section{REFERENCES}

1. Du Bolun, Yang Ruizhen, He Yunze, Wang Feng, Huang Shoudao. Nondestructive inspection, testing and evaluation for si-based, thin film and multijunction solar cells: an overview. Renew Sustain Energy Rev 2017; 78: 1117e51.

2. Villalva, M.G., Gazoli, J.R., Ruppert Filho, E., 2009. Comprehensive approach to modeling and simulation of photovoltaic arrays. IEEE Trans. Power Electron. 24(5), 1198-1208.

3. Balato, M., Costanzo, L., Vitelli, M., "Reconfiguration of PV modules: a tool to get the best compromise between maximization of the extracted power and minimization of localized heating phenomena", Solar Energy $138,105-118$.

4. M. Z. Shams El-Dein, Mehrdad Kazerani, M. M. A. Salama” Optimal Photovoltaic Array Reconfiguration to Reduce Partial Shading Losses", IEEE Transactions on Sustainable Energy, Vol. 4, No. 1, January 2013.

5. Ishaque, K., Salam, Z., Taheri, H., 2011. Modeling and simulation of photovoltaic (PV) system during partial shading based on a two-diode model. Simul. Model. Pract. Theory 19 (7), 1613-1626.
6. Bai, J., Cao, Y., Hao, Y., Zhang, Z., Liu, S., Cao, F., 2015 Characteristic output of PV systems under partial shading or mismatch conditions. Sol Energy 112, 41-54.

7. Bauwens, P., Doutreloigne, J., 2014. Reducing partial shading power loss with an integrated smart bypass. Sol Energy 103, 134-142.

8. G.Sai Krishna, Tukaram Moger, "Comparative Study on Solar Photovoltaic Array Configurations under Irregular Irradiance Conditions", 978-1-5386-4996-1/18/\$31.00 c 2018 IEEE.

9. Okan Bingöl, Burçin Özkaya," Analysis and comparison of different PV array configurations under partial shading conditions", Solar Energy 160 (2018) 336-343.

10. Smita Pareek, Nitin Chaturvedi, Ratna Dahiya, "Optimal interconnections to address partial shading losses in solar photovoltaic arrays", Solar Energy 155 (2017) 537-551.

11. Bidram, A., Davoudi, A., Balog, R.S., 2012. Control and circuit techniques to mitigate partial shading effects in photovoltaic arrays IEEE J. Photovoltaics 2 (4), 532-546.

12. Yadav, A.S., Pachauri, R.K., Chauhan, Y.K., Choudhury, S., Singh, R., "Performance enhancement of partially shaded PV array using novel shade dispersion effect on magic-square puzzle configuration" Sol. Energy 144 (2017), 780-797.

13. Himanshu Sekhar Sahu, Sisir Kumar Nayak, and Sukumar Mishra,' Maximizing the Power Generation of a Partially Shaded PV Array", 2168-6777 (c) 2015 IEEE.

14. V.Balaraju, Dr. Ch. Chengaiah "Performance Analysis of Conventional, Hybrid and Optimal PV Array Configurations of Partially Shaded Modules", International Journal of Engineering and Advanced Technology (IJEAT)', ISSN: 2249-8958 (Online), Vo2lume-9 Issue-1, October 2019, Page No.3061-3073.

15. Ibraheem Nasiruddin, , Mohd Faisal Jalil, R.C. Bansal," Shade diffusion of partial shaded PV array by using odd-even structure", Solar Energy Volume 181, 15 March 2019, Pages 519-529.

16. Pendem Suneel Raju, Suresh Mikkili. Modelling and performance assessment of pv array topologies under partial shading conditions to mitigate the mismatching power losses. Sol Energy 2018; 160:303e21.

17. Anurag Singh Yadav*, V. Mukherjee "Line losses reduction techniques in puzzled PV array configuration under different shading conditions", Solar Energy 171 (2018) 774-783. 